\title{
ARRANJOS PRODUTIVOS DE LATICÍNIOS E A GOVERNANÇA: ESTUDO DE CASO DOS PRODUTORES DE DERIVADOS DE LEITE DO SERTÃO ALAGOANO
}

\author{
Niedja Figueiredo Dantas \\ Professora da Universidade de Pernambuco
}

\begin{abstract}
Resumo - Esta pesquisa teve por objetivo investigar os aspectos da Governança entre os produtores de derivados de leite, que fazem parte do Arranjo Produtivo de Laticínios do Sertão Alagoano. A governança foi estudada nas seguintes dimensões: (1) qualidade das lideranças empresariais, políticas, sindicais e sua relação com os problemas das empresas; (2) construção de centros tecnológicos prestadores de serviço; (3) gestão dos recursos naturais, (4) geração de solidariedade, confiança mútua e atenção para com os problemas sociais; e (5) construção de atitudes positivas no rumo do desenvolvimento técnico, tecnológico e econômico. Os dados foram coletados a partir de questionários e entrevistas semi- estruturadas, com 12 empresários e o gestor do APL em estudo. Entre os resultados encontrados verificou - se que há um distanciamento entre o discurso do Estado e a implantação de ações, no que tange ao apoio ao desenvolvimento tecnológico e em consolidar a liderança na gestão do APL do Sertão, em se tratando da realidade observada dos pequenos produtores de derivados de leite do Sertão Alagoano.
\end{abstract}

Palavras chave: Arranjo Produtivo Local; Governança; Produtores de Laticínios.

\section{PRODUCTIVE ARRANGEMENTS OF LATICÍNIOS AND GOVERNANCE: CASE STUDY OF PRODUCERS OF MILK DERIVATIVES IN SERTÃO ALAGOANO}

\begin{abstract}
This research had the objective to investigate the aspects of the Governance among the producers of milk derivatives that are part of the Productive Arrangement of Dairy products of Sertão Alagoano. According to Cassiolato Pinheiro, 2012, governance is associated with: (1) the quality of business, political, and union leaderships and their relation to business problems; (2) construction of technology centers providing service providers; (3) management of natural resources, (4) generation of solidarity, mutual trust and attention to social problems; And (5) building positive attitudes towards technical, technological and economic development. Data were collected from questionnaires and semi-structured interviews. The results show that there is a gap between the state discourse and the implementation of actions, in terms of support for technological development and in consolidating the leadership in the management of Sertão APL, considering the observed reality of small producers of derivatives Of milk from the Sertão Alagoano.
\end{abstract}

Keywords: Local Productive Arrangement; Governance; Dairy Producers.

\section{INTRODUÇÃO}

Vivemos atualmente a chamada sociedade da informação ou sociedade em rede (CASTELLS, 2005), onde assistimos a troca de conhecimento através das redes de internet, convênios acadêmicos entre universidades e centros de pesquisa, e nas empresas, através de redes de negócios constitui-se na mais importante inovação organizacional associada à difusão de um novo paradigma técnico - econômico, das tecnologias da informação e da economia da informação e do conhecimento. Neste caso, a competitividade das organizações passa a estar relacionada à abrangência das redes em que estão inseridas, a partir das relações que existem entre as empresas participantes fazem das mesmas. 
Estes aspectos nos levam a refletir sobre a questão das redes na ótica do ambiente de negócios. Na primeira década do século XXI temos um cenário de alta competição e corrida pela inovação tecnológica, fazendo com que as empresas atuem de forma conjunta e associada.

Desta forma, pode-se analisar que o crescimento das pequenas e médias empresas organizadas em Arranjos Produtivos Locais está associado a novas arquiteturas organizacionais, assumindo a forma de redes, consórcios, alianças e parcerias, que juntos possam incentivar o desenvolvimento tecnológico, melhorar a competitividade, estimular a troca de know-how entre empresas que fazem parte da cadeia produtiva, bem como pode promover a comercialização de uma marca que seja própria de uma determinada região, com a determinação de atributos que possam favorecer a aceitação dos produtos dos Arranjos Produtivos.

No Brasil, a análise dessas questões enfatizou a investigação das cadeias produtivas. A configuração técnica dos atores envolvidos na cadeia dá-se, preferencialmente, por argumentos relacionados à complementaridade produtiva e, em alguns casos, ao espírito de cooperação. Havendo inclusive uma discussão acerca de tornar os Arranjos Produtivos Locais objeto prioritário das políticas de desenvolvimento econômico e social do país. O Ministério da Indústria e Comércio, no Governo Lula da Silva, desde 2004, promoveu um mapeamento das vocações, potencialidades e dificuldades de um grande número de municípios do Brasil e escolheu 10 Arranjos Produtivos por Estado, nos municípios pré-selecionados. O Governo Dilma também continuou acolhendo e incentivando a execução da Política de Arranjos Produtivos Locais como parte integrante da Política de Desenvolvimento Regional. Desta forma, tem-se trabalhado os Arranjos Produtivos como estratégia de desenvolvimento. O Governo Federal acolhe-os como conceito, ao passo que um número importante de ministérios e agentes públicos vem implantando programas de ações aplicadas em diversos arranjos localizados em todo o território nacional. Enquanto isso, entidades empresariais e suas lideranças têm dedicado grande atenção para as estruturas produtivas concentradas territorialmente.

A competitividade de uma determinada região depende não apenas das indústrias de que dispõe, mas da forma como elas se inserem na competição. Vale dizer, a maior ou menor força competitiva depende cada vez mais do valor contido nas relações interfirmas e interinstituições. Esse contexto fornece um quadro de novas atribuições aos investimentos públicos com vistas a favorecer o aumento da produtividade local. Neste sentido, um estudo sobre governança em Arranjos Produtivos torna - se de relevância social e científica.

As estratégias das firmas passam a ter prioridade as regras, normas e incentivos que contextualizam a governança decorrente da rivalidade / cooperação entre as firmas integrantes do cluster, ou sistema de produção. 
O estudo do APL de Laticínios no Sertão de Alagoas foi realizado em virtude da importância deste aglomerado de empresas, organizados em um APL para a região do Sertão do Estado de Alagoas.

A questão central que norteou esta pesquisa está relacionada a seguinte pergunta: Como acontece a interação entre os empresários que integram o APL de Laticínios em estudo?

Ao se analisar a questão da interação da empresa moderna, observa-se que elas estão cada vez mais próximas não apenas de seus clientes, mas também de seus fornecedores e até mesmo de seus concorrentes. A respeito desta questão, BIDAULT (2009) salienta que as empresas formam alianças estratégicas para desenvolver novas tecnologias, entrar em novos mercados e / ou reduzir custos de fabricação. As alianças muitas vezes são o meio mais rápido e eficiente de atingir objetivos e podem ser importantes não apenas pelo acordo imediato, mas também porque criam oportunidades adicionais e não previstas que abrem portas para o futuro.

Contudo, as alianças podem fracassar se não se desenvolve uma visão clara das expectativas mútuas. Dada a natural resistência das pessoas em mudar, é razoável se esperar choques de cultura e de estilos, quando funcionários de duas ou mais empresas começam a trabalhar juntos, visando a objetivos comuns. A relutância dos parceiros de compartilharem ideias pode chegar a abortar um acordo.

Desta forma, faz-se necessário e relevante este estudo, visando uma melhor compreensão sobre a temática proposta. Assim, este artigo analisa o Arranjo Produtivo de Laticínios no Estado de Alagoas, levando em consideração a questão da governança entre os diversos atores que fazem parte do arranjo, considerando o recorte dos pequenos produtores de derivados de leite.

Está organizado em quatro seções. A primeira seção mostra o histórico do APL de Laticínios do Sertão do Estado de Alagoas. A segunda seção analisa a questão da governança neste APL. A terceira seção apresenta a metodologia da pesquisa. A quarta seção apresenta os resultados. A última seção conclui.

\section{SEÇÃO 1: HISTÓRICO DO ARRANJO PRODUTIVO DE LATICÍNIOS DO SERTÃO DE ALAGOAS}

Arranjos produtivos são aglomerações de empresas e de empreendedores localizados em um mesmo território, que apresentam especialização produtiva e mantêm algum vínculo de articulação, interação, cooperação e aprendizagem entre si e com outros atores locais tais como governo, associações empresariais, instituições de crédito, ensino e pesquisa. (BRASIL, 2014)

Um Arranjo Produtivo Local é caracterizado pela existência da aglomeração de um número significativo de empresas e de empreendedores que atuam em torno de uma atividade 
produtiva principal. Para isso, é preciso a ocorrência de postos de trabalho, faturamento, mercado, potencial de crescimento, diversificação, entre outros aspectos.

A região da bacia leiteira alagoana configurou-se há cerca de 80 anos e tornou-se conhecida nacionalmente por sua alta produção diária de leite e boa qualidade genética do rebanho bovino. Durante muitos anos a região destacou-se exercendo um papel importante na economia alagoana.

Em 2000, a bacia leiteira de Alagoas formava o maior centro produtor in natura de leite da Região Nordeste do Brasil. (SEPLAN/ AL, 2014)

Contudo, atualmente essa atividade enfrenta sérios problemas de competitividade, por diversos motivos, especialmente no segmento de pequenos produtores. Isso pode ser evidenciado pela queda de produção de leite em cerca de $30 \%$, na última década. A importância desta atividade na economia dos municípios integrantes da bacia leiteira é tão significativa que quando a produção está fragilizada, toda a economia dos municípios é afetada, provocando séria crise no comércio local.

No ano de 2016, o Estado de Alagoas possui a terceira mais importante bacia Leiteira do Nordeste. Na década de 90 era a primeira bacia leiteira do Nordeste. Atualmente, cerca de 70 a $80 \%$ dos produtores de leite, de toda a cadeia de laticínios, são considerados pequenos.

Dentre todos os produtores desta cadeia, $40 \%$ produz 50 litros/leite/dia, e apenas $7 \%$ produz acima de 500 litros/dia. (SEPLAN/ AL, 2015)

A cada ano, essa cadeia se expande nos pólos de Viçosa e União dos Palmares, assim como no vale do Rio Paraíba, na zona da mata alagoana, e também no litoral norte, que começa a despontar na atividade leiteira.

Contudo, a maior parte do leite produzido no estado ainda se concentra na região do sertão (60,57\% da produção total), apesar da falta de mão-de-obra qualificada e de abastecimento de água. (SEPLAN/AL, 2014)

Apesar disso, a bovinocultura ainda se configura como um negócio promissor na região do Médio Sertão Alagoano, Microrregião de Batalha, segundo a divisão socioeconômica estadual, devido a sua tradição e adaptabilidade às condições locais.

Para localização geográfica do Arranjo Produtivo de Laticínios do Sertão Alagoano, observe o mapa do Estado de Alagoas, que segue: 


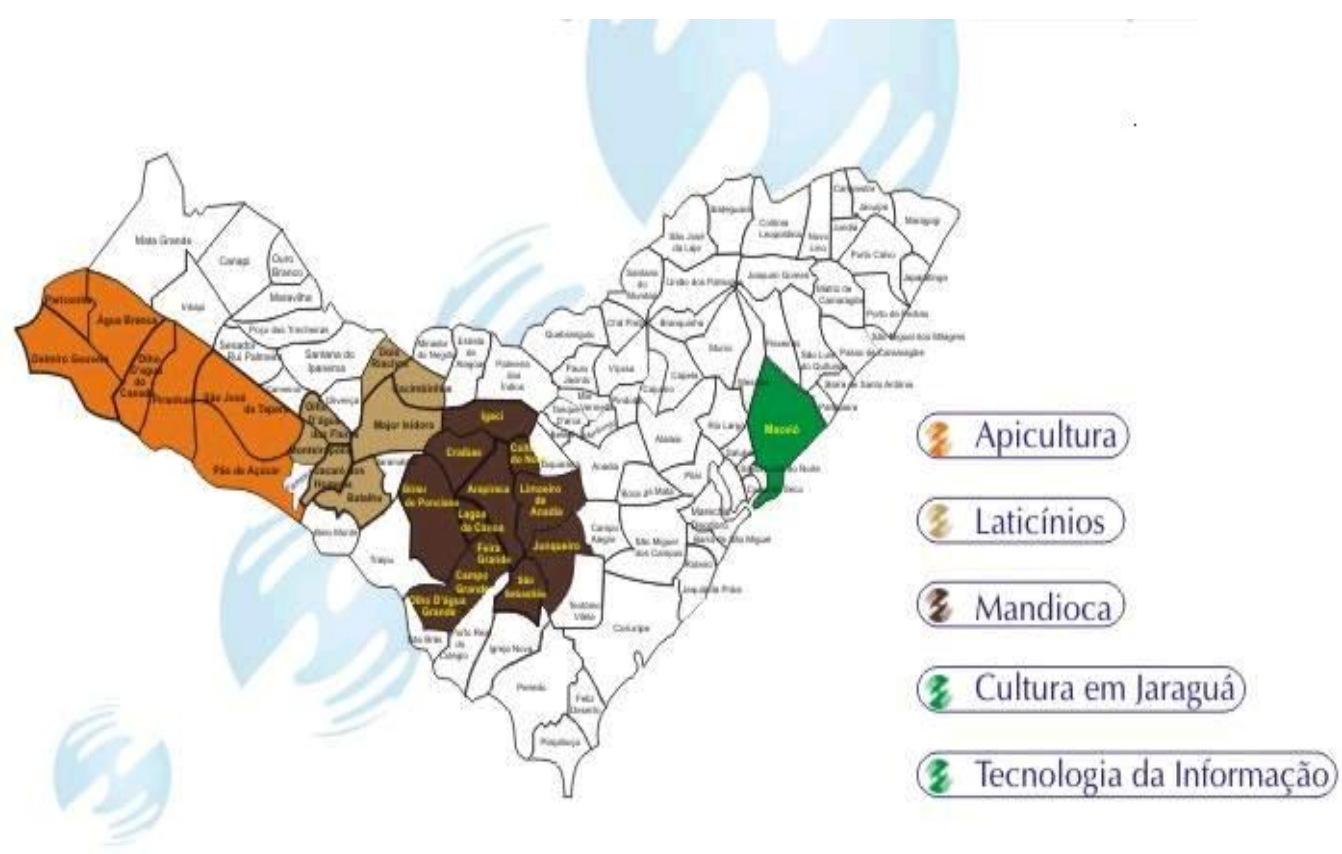

\section{HISTÓRICO DOS PEQUENOS PRODUTORES RURAIS DE DERIVADOS DE LEITE DO SERTÃO ALAGOANO.}

Os municípios de Major Izidoro, Cacimbinhas, Batalha, Jacaré dos Homens, Monteirópolis, Olho D’Água das Flores e Santana do Ipanema, localizam-se no Sertão Alagoano e, por apresentarem características comuns, constituem um território. Nestes municípios a atividade de laticínio é uma atividade antiga e representa a economia do território e principal atividade do local.

A atividade no território data de aproximadamente 80 anos, segundo dados de informações da população do município de Major Izidoro.

Contribui para a cadeia produtiva do leite, como também na ocupação da mão-de-obra local e principal fonte econômica do território.

Desse modo, a densidade empresarial das fábricas configura o território produtivo de laticínios nos municípios de Major Izidoro, Batalha e Cacimbinhas (concentração de 60,57\% produção da região). Este Território concentra cerca de $30 \%$ da produção do estado, onde se tem como especialização produtiva os queijos tipos coalho e manteiga, e bebidas lácteas - que tem como principal matéria-prima o soro gerado no processo de fabricação do queijo coalho. (SEPLAN/ AL, 2014)

No caso específico do território produtivo de laticínios da bacia leiteira do Sertão Alagoano, o município de Major Izidoro se destaca no Estado como sendo o referencial da Bacia Leiteira Alagoana. Produção alta, boa qualidade genética do rebanho bovino, clima favorável e longa experiência no ramo por parte dos produtores. Por este motivo, a região ficou conhecida por sua vocação para pecuária bovina leiteira, onde por muitos anos se destacou 
exercendo um papel importante na economia alagoana e da região. Contudo, atualmente esta atividade enfrenta sérios problemas de competitividade, por diversos motivos, especialmente no segmento de pequenos produtores.

A produção de derivados de leite beneficiada nos municípios do Sertão Alagoano é desordenada e artesanal, não seguindo nenhum padrão de qualidade. Atualmente, existem cerca de 2.000 produtores de leite e aproximadamente 200 fabricantes de laticínios no território, entre fabriquetas e produção caseira com fins comerciais, que estão à margem de um processo produtivo, pela não adequação à legislação em vigor. Em relação à produção diária de derivados do leite, cada fabriqueta produz em média de $120 \mathrm{Kg}$ de queijo coalho por dia. Algumas das fábricas produzem outros derivados do leite, como iogurte, bebida láctea, queijo manteiga e manteiga em pasta e em garrafa. Em relação á quantidade de empregos gerados pela atividade neste território, tem-se cerca de 95 formais e 1500 informais. (SEPLAN/ AL, 2014)

Apenas o município de Major Izidoro possui um certo nível de organização da atividade no território, pois das cerca de 69 fabricas existentes neste município, apenas 12 estão devidamente regularizadas e podem comercializar a sua produção dentro do estado. Apenas duas possuem SIF Serviço de Inspeção Federal e assim podem realizar a comercialização nacional.

As demais fábricas apresentam uma produção praticamente artesanal, com condições precárias de higiene e infra-estrutura. Como a maioria não está legalizada, a comercialização da produção se dá de forma clandestina, e o escoamento dos produtos (principalmente do queijo tipo coalho) ocorre pela madrugada, nas estradas vicinais, de modo a desviarem da fiscalização.

\section{SEÇÃO 2: A GOVERNANÇA NOS ARRANJOS PRODUTIVOS LOCAIS}

Segundo Lastres e Cassiolato, 2006 os Arranjos Produtivos Locais constituem um tipo particular de cluster, formado por pequenas e médias empresas, agrupadas em torno de um negócio, onde se enfatiza o papel desempenhado pelos relacionamentos - formais e informais entre empresas e demais instituições envolvidas. As firmas compartilham uma cultura comum e interagem, como um grupo, com o ambiente sociocultural local. Essas interações, de natureza cooperativa e/ou competitiva, estendem-se além do relacionamento comercial e tendem a gerar, afora os ganhos de escala, economias externas, associadas à socialização do conhecimento e à redução dos custos de transação.

Ao final dos anos 80 a concepção de Arranjos Produtivos foi ampliada para incluir aspectos relacionados à investigação das relações entre os diversos atores estabelecidos na cadeia produtiva. A interdependência entre eles na busca de soluções em ambientes socioeconômicos comuns passou a ser tratada como categoria analítica. A resultante lógica foi de que a criação de novas forças competitivas se encontrava na possibilidade de movimentos e 
ações compartilhados entre atores com objetivos convergentes. $\mathrm{O}$ alcance da competitividade das empresas relacionou-se, assim, às novas formas de sistemas locais de produção.

Esse modelo de sistemas locais de produção apoiou-se na experiência internacional que já vinha revelando formas de organização industrial originais, notadamente nos Estados Unidos, na região do Vale do Silício, nos países da União Européia (principalmente França, Reino Unido e Alemanha) e na Itália, com a criação de distritos industriais (Terceira Itália). Essas novas formas organizacionais, guardadas as proporções, foram denominadas de clusters industriais. (CASSIOLATO apud PINHEIRO, 2012)

De fato, a organização de empresa em clusters apresenta facilidades para a conciliação entre as trajetórias tecnológicas de diversificação e padronização de produtos, já que estabelece oportunidades à entrada de novas firmas e propicia um ambiente adequado ao fortalecimento de capacitações tecnológicas integradas entre empresas. (PYKE apud PINHEIRO 2002). Ademais, sob certas condições históricas de formação dos clusters, os vínculos que se estabelecem entre as empresas regionais podem ampliar espaços culturais para absorver e ao mesmo tempo lançar certos valores, costumes e comportamentos originais, consolidando uma identidade na região. A ampliação de mercados, o poder de negociação, a imagem dos produtos, a facilidade de crédito, a distribuição dos produtos, por exemplo, são fatores fortalecidos numa estratégia modelada em termos de clusters.

As empresas em um cluster podem, de forma cooperativa, criar a infra-estrutura complementar para conseguir financiamento, ou formar uma unidade de pressão sobre as autoridades para obter elementos necessários ao desenvolvimento de seus projetos. Como o sistema é de ação conjunta entre empresas, através de alianças explícitas ou tácitas, Joint Ventures, redes de empresas integradas ou de outras formas de organização empresarial/ industrial, os investimentos necessários à manutenção do cluster, com vistas a padronizar suas produções diversificadas, podem ser rateados entre todos. A sinergia governamental com a indústria privada é máxima nesse caso, beneficiando tanto a produção local quanto a de produtos exportáveis.

Entre as vantagens econômicas da constituição de clusters, uma das principais é o aumento da competitividade dos produtos neles produzidos. O alcance dessas vantagens é atribuído à intervenção e à participação das diversas categorias de atores envolvidos no processo de decisão local.

Daí a importância do conceito de governança, pois para a constituição do cluster e o seu desenvolvimento surgem situações em que alguma forma de coordenação e controle, conduzida pelas interações das lideranças locais com diversos outros atores, condiciona e induz a forma como se organiza o coletivo. 
$\mathrm{Na}$ verdade, não é condição suficiente o fato de as empresas estarem dispostas em local regionalmente definido ou mesmo estabelecerem ligações para a frente e para trás na cadeia vertical produtiva com firmas e instituições afins, para que as potencialidades competitivas sejam efetivadas. Em um mundo crescentemente globalizado, as interações entre os agentes locais relacionam-se com o resultado de outras interações estabelecidas em outras localidades. O reconhecimento dos processos de relacionamento dos atores traduz-se como condição necessária às ações de políticas públicas para a constituição e o desenvolvimento de clusters.

Segundo Cassiolato (apud Pinheiro, 2002), a governança está associada à:

(1) qualidade das lideranças empresariais, políticas, sindicais e sua relação com os problemas das empresas; (2) construção de centros tecnológicos prestadores de serviço estruturas que as empresas não poderiam suportar de forma isolada, que cumprem o papel que os núcleos de pesquisa e desenvolvimento (P\&D) e recursos humanos desempenham nas grandes empresas; (3) gestão dos recursos naturais, (4) geração de solidariedade, confiança mútua e atenção para com os problemas sociais; e (5) construção de atitudes positivas no rumo do desenvolvimento técnico, tecnológico e econômico.

Quando se considera a questão da governança no Arranjo Produtivo de Laticínios do Sertão Alagoano, o município de Major Isidoro apresenta-se como o principal ator na liderança, participação e negociação dos conflitos nos processos decisórios locais dessa região, devido à existência de um grupo de produtores que se encontra organizado através da Associação Comercial, pelo Núcleo de Queijarias de projeto Empreender. A existência e atuação do mencionado núcleo fazem com que o município assuma a governança desse território.

Percebe-se também que há uma enorme dificuldade com relação a mão de obra qualificada, com a visão dos proprietários, que ainda falta muito para que eles tenham uma visão estratégica, para que façam um planejamento que abranja todas a áreas desde marketing, tecnologia, financeiro e comercial.

O relatório da Secretaria de Planejamento do Estado de Alagoas - SEPLAN, 2014 apontou que há uma ausência de ações no sentido de orientação pela busca de novos mercados, não sendo identificado nenhum plano de expansão em busca de mercados mais adequados a um produto na maioria das vezes artesanal.

A relação dos pequenos produtores de derivados de leite do Sertão Alagoano com os clientes acontece de forma muito precária, levando em consideração que a maior parte é informal, não podendo divulgar publicamente seus produtos, como também, as vendas acontecem na maioria das vezes por intermédio de atravessadores que comercializam os produtos em feiras livres dos Estados de Alagoas e Pernambuco. 
Políticas públicas devem avançar em direção a ações de estímulo e incentivo à competitividade local, visando com que esta transformar-se em competitividade nacional. Isso significa que as ações de políticas públicas não são triviais, pois devem propiciar uma forma de governança ampla das atividades produtivas adequadas ao equacionamento das questões relacionadas ao padrão de alta concorrência.

Nesta parte do artigo a nossa reflexão é demarcada em relação aos Arranjos Produtivos Locais, enquanto sistema de produção, que necessita de um conjunto de ações de articulação, sensibilização e mobilização para desencadear o processo de envolvimento e aproximação entre os atores locais.

Assim, pode-se refletir a problemática da governança a partir da análise dos diferentes modos de liderança, coordenação, intervenção, participação e negociação dos conflitos nos processos decisórios locais. Esta questão diz respeito ao fortalecimento da dinâmica do Arranjo, considerando a Articulação, Sensibilização e Mobilização dos Atores Locais. A governança pode envolver pessoas físicas ou jurídicas que estejam ligadas às funções de investimento nas redes, com real ou potencial capacidade de coordenar as relações econômicas e tecnológicas no âmbito local.

A busca de soluções para problemas comuns entre as empresas participantes do APL pode gerar a governança e o desenvolvimento de forças compartilhadas, que podem ter como conseqüência o aumento da competitividade das empresas. Essas forças incluem: troca de tecnologia, diversificação de produtos, padronização da qualidade, consolidação da identidade de uma região que se pode refletir na associação da marca dos produtos ao lugar; além da ampliação de mercados e poder de negociação. A governança pode buscar ações que favoreçam a competitividade, através da integração do setor produtivo, governo, universidades e demais atores da cadeia produtiva pertencentes ao APL.

\section{SEÇÃO 3: METODOLOGIA DA PESQUISA}

Trata-se de uma pesquisa qualitativa, que segundo Vergara (2008) é considerada mais adequada para a investigação de valores, atitudes, percepções e motivações do público pesquisado, com a preocupação primordial de entendê-los, em maior profundidade.

O universo desta pesquisa está delimitado nos 200 pequenos produtores de derivados de leite do Sertão Alagoano, pertencentes ao Arranjo Produtivo de Laticínios do Sertão.

No primeiro momento foi realizada uma pesquisa bibliográfica com revisão da literatura acerca da Governança e sobre Arranjo Produtivo Local. Analisou-se também relatórios da Secretaria de Planejamento do Estado de Alagoas, acerca dos Arranjos Produtivos deste Estado. 
No segundo momento foram realizadas entrevistas semiestruturadas, visando colher informações sobre a real situação do APL de Laticínios do Sertão no Estado de Alagoas, realizando um recorte para maior aprofundamento do estudo, considerando os produtores de derivados de leite do Sertão de Alagoas, que são os pequenos empresários que fabricam queijo e manteiga. Foram realizadas entrevistas junto aos gestores do APL de Laticínios do Sertão Alagoano, para complementar os dados coletados no levantamento de campo. Totalizando 12 entrevistas, o que impede inferências para o todo. Desta forma o limite desta pesquisa refere-se ao ponto de vista dos dados coletados, junto aos respondentes (produtores de derivados de leite do Sertão Alagoano e gestor do Arranjo Produtivo de Laticínios do Sertão).

\section{SEÇÃO 4: ANÁLISE DOS RESULTADOS:}

Em se tratando do APL de Laticínios do Sertão de Alagoas a produção de leite beneficiada no próprio município é desordenada e artesanal, não seguindo nenhum padrão de qualidade. Atualmente, existem cerca de 2.000 produtores de leite e aproximadamente 200 fabricantes de laticínios no território, entre fabriquetas e produção caseira com fins comerciais, que estão à margem de um processo produtivo, pela não adequação à legislação em vigor.

Apenas o município de Major Izidoro possui um certo nível de organização da atividade no território, pois das cerca de 69 fábricas existentes no município, apenas 12 estão devidamente regularizadas e podem comercializar a sua produção dentro do estado. Apenas duas possuem SIF Serviço de Inspeção Federal e assim podem realizar a comercialização nacional. (SEPLAN/AL, 2014)

\section{(1) QUALIDADE DAS LIDERANÇAS EMPRESARIAIS, POLÍTICAS, SINDICAIS E SUA RELAÇÃO COM OS PROBLEMAS DAS EMPRESAS:}

Observa-se falta de apoio do Estado, que poderia promover políticas que suprimissem alguns dos principais problemas dos pequenos produtores de derivados de laticínios do Sertão Alagoano. Instituições como a UFAL - Universidade Federal de Alagoas, poderia fornecer novas tecnologias através de seu curso de agronomia, tecnologia aplicada a processamento de produtos derivados de laticínios. A Secretaria de Agricultura do Estado poderia proporcionar acordos de cooperação internacional, entre produtores de queijo do Sertão Alagoano e produtores de queijo de outros países, que possuem tradição nestes produtos, como a Itália, por exemplo.

Quando se analisa mais de perto a questão da governança no APL de Laticínios, observase que existe falta de lideranças que conduzam o processo, falta articulação política da parte dos produtores de derivados de laticínios, por falta de cultura associativa entre os pequenos produtores de derivados de leite dos vários municípios do Sertão Alagoano.

"Não sei o significado de governança no APL, não participo de reuniões" (Empresário do APL)

REVISTA ECONOMIA POLÍTICA DO DESENVOLVIMENTO $\quad$ Maceió - AL $\quad$ V.2 N.3. JUNHO/2015 P.90-102 Página-98




\section{(2) CONSTRUÇÃo DE CENTROS TECNOLÓgICOS PRESTADORES DE SERVIÇO}

Considerando-se a realidade dos pequenos produtores de derivados de leite do Sertão Alagoano não se tem observado apoio das instituições que são parceiras do APL, principalmente da Universidade Federal do Estado de Alagoas e o Centro Tecnológico - CEFET-AL. Além disso as entrevistas revelaram resistência dos produtores em aceitar novas tecnologias.

"Não existe intercâmbio tecnológico entre os produtores de derivados de leite de outros Estados" (Empresário do APL)

"Não vejo a necessidade de novas tecnologias" (Empresário do APL)

“... E está entre as metas do SEBRAE/AL facilitar a implantação de um Centro Tecnológico de Laticínios no Sertão de Alagoas" (gestor do APL de Laticínios do Sertão Alagoano)

\section{(3) GESTÃO DOS RECURSOS NATURAIS}

As entrevistas apontam que os pequenos produtores rurais de derivados de leite do Sertão Alagoano não têm se preocupado com a questão ambiental.

"Na produção de queijos não há impacto no meio ambiente" (Empresário do APL)

\section{(4) GERAÇÃO DE SOLIDARIEDADE, CONFIANÇA MÚTUA E ATENÇÃo PARA COM OS PROBLEMAS SOCIAIS;}

As entrevistas apontam na direção da falta de uma cultura associativa, que compromete a formação de uma confiança mútua e discussão acerca dos problemas em comum. Falta comunicação e comprometimento dos elos da cadeia produtiva.

"porque eu iria dividir o conhecimento do meu negócio com o concorrente?" (Empresário do APL)

\section{(5) CONSTRUÇÃO DE ATITUDES POSITIVAS NO RUMO DO DESENVOLVIMENTO TÉCNICO, TECNOLÓGICO E ECONÔMICO.}

Quando se analisa as atitudes de instituições que poderiam promover o desenvolvimento técnico, tecnológico e econômico verifica-se que instituições como Banco do Nordeste, Sebrae/AL, Universidade Federal de AL / UFAL, Secretaria de agricultura do Estado, Vigilância Sanitária, SENAI /AL, SENAR, EMBRAPA e Secretaria Executiva da Indústria e Comércio do Estado, no discurso, estas instituições estão prontas para prestar o apoio necessário. Contudo ainda não foram observadas ações efetivas junto aos pequenos produtores de leite no que diz respeito a 
crédito, e desenvolvimento de novas tecnologias de processamento de queijos, que poderiam tornar a região mais competitiva, em se tratando da melhoria dos produtos atuais e em relação ao desenvolvimento de novos produtos, como por exemplo novos tipos de queijo.

\begin{abstract}
“... as estratégias tecnológicas previstas para serem implantadas neste Arranjo são; 1) Implantar melhorias no processo produtivo, através de consultoria às empresas, com técnica especializada, aplicadas no desenvolvimento e na diversificação dos produtos lácteos; 2) Implantação do Programa Alimentos Seguros, através da implantação de Boas Práticas de Fabricação -BPF e Análise de Perigos e Pontos Críticos de Controle; 3) Diagnóstico Setorial, para levantamento de gargalos do setor e 4) Diagnóstico Individual nas empresas" (segundo entrevista com técnico do SEBRAE/AL, o gestor do Arranjo Produtivo de Laticínios do Sertão Alagoano).
\end{abstract}

\title{
CONCLUSÃO
}

Os resultados apontam a existência de uma enorme dificuldade com relação a mão de obra qualificada, na visão dos pequenos produtores de derivados de leite do Sertão Alagoano, ainda falta muito para que eles tenham uma visão estratégica, para que façam um planejamento que abranja todas a áreas desde marketing, tecnologia, financeiro e comercial.

Há ausência de ações no sentido de orientação pela busca de novos mercados, não sendo identificado nenhum plano de expansão em busca de mercados mais adequados a um produto na maioria das vezes artesanal.

Ao se analisar a relação dos empresários com os clientes entre os pequenos produtores de derivados de leite do Sertão Alagoano, as relações acontecem de forma muito precária, levando em consideração que a maior parte é informal, não podendo divulgar publicamente seus produtos, como também, as vendas acontecem na maioria das vezes por intermédio de atravessadores que comercializam os produtos em feiras livres dos Estados de Alagoas e Pernambuco.

Observa-se que existe um distanciamento do Governo Federal, através do Ministério da Agricultura, que poderia colaborar com a melhoria do serviço do APL de Laticínios fazendo com que se pudesse se tornar competitivo, no entanto a colaboração ainda não está acontecendo. O que se verifica, a partir das entrevistas realizadas, é a ausência do Estado no nível Federal, Estadual, e Municipal, no que tange a vários desafios que os produtores de derivados de leite enfrentam. Segundo discurso de técnicos da Secretaria de Planejamento do Estado de Alagoas, podem -se citar: Crédito incompatível com a realidade do setor; Estradas vicinais necessitando recapeamento e manutenção; Ausência de políticas de extensão, pesquisa e desenvolvimento; Carga tributária elevada; insuficiente e inadequada política de combate a desnutrição, miséria e pobreza; Ciclo da seca que desmotiva a ampliação de pequenos produtores; Abastecimento deficiente de água que exige ações mais efetivas; Falta de técnicos na estrutura da Secretaria da Agricultura para o controle sanitário do rebanho. 
Conforme discutido nas seções anteriores, a forma de organização das empresas em clusters associam como fatores predominantes para o desenvolvimento das PME's à construção de alianças, parcerias, consórcios, que almejem a formação de Arranjos Produtivos Locais.

Entretanto, estas formas associativas ainda não são realidade quando se estuda em profundidade a situação dos pequenos produtores de derivados de leite do Arranjo Produtivo de Laticínios do Sertão de Alagoas. Faz-se necessário o desenvolvimento de políticas públicas direcionadas a fomentar a competitividade dos pequenos produtores de derivados de leite do Sertão Alagoano, que de modo a facilitar o crédito, o desenvolvimento tecnológico e a pesquisa e desenvolvimento de novos produtos e cooperação entre produtores de outros estados ou de outros países, que tenham tradição na produção de queijos, iogurtes, manteigas e outros produtos lácteos. Assim como faz-se também necessário uma aproximação maior da Universidade e Centros Tecnológicos, que possam fornecer novas tecnologias de processo produtivo.

A consolidação de uma governança consolidada, baseada na confiança e no relacionamento junto as instituições de fomento, poderia contribuir para alavancar a competitividade, melhorar a qualidade, bem como desenvolver novos produtos e promover a inserção destes em novos mercados.

Faz-s necessário que o apoio não seja apenas momentâneo, é necessário que seja sistemático e contínuo para que seja consolidada uma governança que busque numa competitividade sustentável, com produtos de qualidade e inovadores e marcas fortes, baseada nos atributos do lugar, de modo que o Sertão Alagoano possa ser referência na produção de derivados de leite. A promoção da competitividade das firmas participantes do Arranjo Produtivo de Laticínios do Sertão é conseqüência da consolidação de uma governança baseada nos atributos vistos nesta pesquisa.

\section{REFERÊNCIAS BIBLIOGRÁFICAS}

BIDAULT, Francis; CUMMINGS, Thomas. Os benefícios ocultos das alianças. Jornal Gazeta Mercantil. São Paulo: Caderno Especial: O Domínio da Administração. n 19. 02 janeiro 2009, p. 13-15.

BRASIL, Ministério da Indústria e Comércio. Relatório do Grupo de Trabalho para Arranjos Produtivos Locais. Brasília, 2004.

CASSIOLATO, J E. Globalização e Inovação localizada. Rio de Janeiro: IE/UFRJ, 2001, mimeo in PINHEIRO, Armando Castelar; MARKWALD, Ricardo; PEREIRA, Lia Valls. O desafio das exportações. Rio de Janeiro: BNDES, 2012.

CASTEllS, Manuel. A Era da Informação: Economia, Sociedade e Cultura. V1. A Sociedade em Rede. $8^{\text {a }}$. Ed. São Paulo: Paz e Terra, 2005.

FEIJÓ, Jandira; FRANCO Augusto de, (org). Olhares sobre a experiência da Governança Solidária Local de Porto Alegre. Porto Alegre: EDIPUCS, 2008. 
LAGES, Vinícius; TONHOLO, Josealdo. (organizadores). Desafios de Competitividade em Arranjos Produtivos Locais: dinâmicas de inovação e papel das incubadoras de empresas e parques tecnológicos. Brasília: ANPROTEC, 2010.

LASTRES, Helena M. M.; CASSIOLATO, José E. Estratégias para o Desenvolvimento: um enfoque sobre Arranjos Produtivos Locais do Norte, Nordeste e Centro Oeste Brasileiros. Rio de Janeiro: Epapers, 2006.

MONIÉ, Fredéric; SILVA, Gerardo (organizadores). A Mobilização Produtiva dos Territórios: instituições e logística do desenvolvimento local. Rio de Janeiro: DP\&A editora, 2003.

PINHEIRO, Armando Castelar; MARKWALD, Ricardo; PEREIRA, Lia Valls. O desafio das exportações. Rio de Janeiro: BNDES, 2002.

SEPLAN/ AL - Secretaria de Planejamento do Estado de Alagoas. Plano de Ação: APL de Laticínios

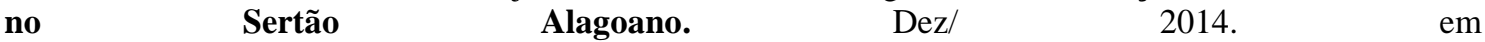
http:www.planejamento.al.gov.br/projetos\%20e\%programas/apls/papl/...apl...laticinios. Acessado em 22/02/2016

URANI, André; COCCO, Giuseppe; GALVÃO, Alexandre Patez (organizadores). Empresários e empregos nos novos territórios produtivos: o caso da Terceira Itália._Rio de Janeiro: DP\&A, 2009.

VALE, Gláucia Maria Vasconcellos. Territórios Vitoriosos: o papel das redes organizacionais. Rio de Janeiro: Editora Garamond Ltda, 2007.

VERGARA, Sylvia. Projetos de Pesquisa em Administração. São Paulo: Atlas, 2008. 